\title{
Repetition proportion biases masked priming of lexical decisions
}

\author{
GLEN E. BODNER \\ University of Calgary, Calgary, Alberta, Canada \\ MICHAEL E. J. MASSON \\ University of Victoria, Victoria, British Columbia, Canada \\ and \\ NORANN T. RICHARD \\ University of Calgary, Calgary, Alberta, Canada
}

\begin{abstract}
Although subjects have little or no awareness of masked primes, Bodner and Masson (2001) found that priming of lexical decisions is often enhanced when masked repetition primes occur on a high proportion of trials. We used baseline prime conditions to specify the locus of this repetition proportion (RP) effect. In Experiments 1A and 1B, a .8-RP group showed more priming than did a .2-RP group, and this RP effect was due to both (1) increased facilitation from repetition primes and (2) increased interference from unrelated primes. In Experiment 2, we used the baseline condition to show that subjects are sensitive to RP rather than to the proportion of unrelated primes. Direct comparisons of a given prime condition (repetition, unrelated) across RP conditions were more stable than were comparisons relative to the baseline condition. The increased costs and benefits of repetition priming when $\mathrm{RP}$ is higher implicate a context-sensitive mechanism that constrains accounts of masked priming.
\end{abstract}

In the three-field masked priming paradigm, a mask (e.g., XXXx) is immediately followed by a brief prime (e.g., cake; $45 \mathrm{msec}$ ), and a target immediately follows the prime (e.g., CAKE). This arrangement largely prevents conscious awareness of the prime, allowing researchers to examine how decisions about the targets are influenced by particular prime-target relationships. In Forster and Davis's (1984) classic study, subjects made accurate lexical (i.e., word vs. nonword) decisions to word targets more quickly when the masked prime was a repetition of the target (e.g., cake-CAKE) rather than an unrelated word (e.g., boot-CAKE). In the present article, we also examine masked repetition priming in the lexical decision task, although other kinds of masked primes (e.g., orthographic, phonological, semantic) could have been used to facilitate responses, and other tasks could have been used to assess priming (e.g., naming, semantic categorization).

The Natural Sciences and Engineering Research Council of Canada supported this research through Discovery Grants to G.E.B. and M.E.J.M. and through two Undergraduate Student Research Awards to N.T.R Thanks to Marnie Jedynak, Tanjeem Azad, and Andreas Breuer for their assistance. N.T.R. is now in the Department of Psychology at Simon Fraser University. Correspondence concerning this article should be addressed to G. E. Bodner, Department of Psychology, University of Calgary, 2500 University Drive NW, Calgary, AB, T2N 1N4 Canada (e-mail: bodner@ ucalgary.ca).

Note-This article was accepted by the previous editorial team, when Colin M. MacLeod was Editor.
Kinoshita and Lupker (2003) provide several examples of research questions that have been investigated with this methodological tool over the past two decades.

We have been using this paradigm to examine whether the cognitive system can use masked primes in a flexible manner to guide task performance (Bodner \& Dypvik, 2005; Bodner \& Masson, 2001, 2003, 2004). When the target context is manipulated (e.g., varying the types or proportions of word and/or nonword targets), subjects are aware of this context and thus can set their processing strategies accordingly. For example, in a lexical decision task, use of pseudohomophone nonword targets (e.g., BRANE) can lead subjects to decrease their reliance on phonology, whereas use of consonant string nonword targets (e.g., SHTGS) can lead them to increase their reliance on familiarity (e.g., Bodner \& Masson, 1997; Stone \& Van Orden, 1993). In contrast, because subjects have little or no awareness of masked primes, the cognitive system's sensitivity to regularities in the prime context can be investigated independently of guidance from conscious strategies. As described next, we have been examining the surprising finding that masked priming is often influenced by the probability that the prime on a given trial provides useful information for processing its target.

\section{Evidence of Prime-Proportion Effects on Masked Priming}

Bodner and Masson (2001) varied the proportion of repetition-prime trials (hereafter referred to as RP, for rep- 
etition proportion) in the stimulus list across two groups of subjects in a lexical decision task. One group received an RP of .8, and the other received an RP of .2; unrelated primes preceded the remaining targets. Masked repetition priming was greater when the RP was .8, and this RP effect was observed across a variety of contextual manipulations (e.g., word target frequency, nonword target type, target format, prime duration). Although RP did not always influence priming (e.g., under a high degree of trial-to-trial variation in target processing difficulty), other studies have since obtained prime-proportion effects with masked primes.

Bodner and Masson (2004) found an RP effect in the naming task, showing that prime-proportion effects can also occur in nonbinary-response identification tasks (although they have yet to be observed in the masked word identification task; Brysbaert, 2001; Pecher, Zeelenberg, \& Raaijmakers, 2002). Returning to the lexical decision task, Bodner and Masson (2003) found that the benefit from a semantic prime-target relationship (e.g., doctorNURSE vs. truck-NURSE) also increased when .8 rather than .2 of the trials involved semantic primes (i.e., a relatedness proportion effect; see Neely, 1991, for a review). Primeproportion effects have also been obtained with stimuli other than words. Bodner and Dypvik (2005) found that parity (i.e., odd/even) and magnitude (i.e., less/more than 5) judgments to digit targets were influenced by masked primes to a greater extent when .8 rather than .2 of the trials involved response-congruent primes. Jaskowski, Skalska, and Verleger (2003) presented pairs of squares to subjects and asked them to indicate whether the left or right square was missing a pair of segments. Masked presentation of the target square on the congruent (vs. incongruent) side produced more priming when side-congruent primes occurred on .8 rather than .2 of the trials.

\section{Accounts of Prime-Proportion Effects on Masked Priming}

These demonstrations of proportion-dependent variations in priming suggest that the cognitive system has the ability to modulate the influence of masked primes in an adaptive manner. To explain prime-proportion effects, as well as other masked-priming phenomena, we have developed a memory-recruitment account of priming (Bodner \& Dypvik, 2005; Bodner \& Masson, 1997, 2001, 2003, 2004; Masson \& Bodner, 2003) inspired by Whittlesea and Jacoby's (1990) retrieval account of priming. The basic assumption of the account is that the processing operations applied to the prime to identify and interpret it form a new memory representation (e.g., Kolers \& Roediger, 1984; Logan, 1988). This processing instance can then be used, without awareness, to assist with processing of a subsequent target. Recruitment of this learning experience is more likely when the processing operations performed on the prime and those needed to process and respond to the target are transfer appropriate (e.g., Morris, Bransford, \& Franks, 1977). Thus, a context containing a high proportion of task-useful primes cues the cognitive system to increase prime recruitment to facilitate target processing (e.g., Allen \& Jacoby, 1990; Jacoby, 1983).
We have suggested (Bodner \& Masson, 1998) that the memory-recruitment account is consistent with Anderson's rational analysis of memory (Anderson \& Milson, 1989; Anderson \& Schooler, 1991; Schooler \& Anderson, 1997). In this analysis, memory retrieval is tuned to memories that are most likely to be relevant in the current situation, with relevance determined by the historical structure of the environment. In their rational analysis of memory retrieval in semantic priming, for example, Anderson and Milson proposed that speed of retrieving a target word (e.g., cat) would depend on the ratio of the probability of needing the target in the context of the prime word (e.g., $d o g$ ), relative to the overall probability of needing the target word, as shown in Equation 1:

$$
\text { need ratio }=\frac{p(\text { cat } \text { is needed } \mid d o g \text { is the prime })}{p(\text { cat } \text { is needed })} .
$$

In the case of related word pairs, the former probability is larger than the latter, producing a need ratio greater than 1.0. In the rational analysis account of memory retrieval, items with larger need probabilities are retrieved first and will therefore be associated with shorter response latencies. Items with lower need ratios will take longer to retrieve. Moreover, targets presented with unrelated primes will have need ratios less than 1.0 and may show an interference effect, relative to a baseline prime condition (Anderson \& Milson, 1989, p. 712). We assume that need probabilities can be modified by ongoing environmental events, such as RP. With a high RP, the need probability for a word corresponding to a masked repetition prime is particularly high because primes are very frequently followed by identical targets. This increase in conditional probability will elevate the need ratio for a repetition primed target, as shown in Equation 2:

$$
\text { need } \text { ratio }=\frac{p(\text { word } 1 \text { is needed } \mid \text { word } 1 \text { is the prime })}{p(\text { word } 1 \text { is needed })} \text {. }
$$

Under these conditions, the prime word is readily available for retrieval and, because it matches the target, a processing advantage will ensue. A complementary effect of the high-RP environment is to reduce the conditional probability of needing any word that does not match the prime. Thus, the need ratio for a target that follows an unrelated prime will be reduced, as implied by Equation 3:

$$
\text { need ratio }=\frac{p(\text { word } 2 \text { is needed } \mid \text { word } 1 \text { is the prime })}{p(\text { word } 2 \text { is needed })} \text {. }
$$

On unrelated trials, the elevated need ratio for the unrelated prime reduces the need ratio for the target, leading to reduced efficiency in processing targets on these trials. Thus, a high RP should both improve response efficiency (reduce latency and/or errors) when repetition primes are presented and reduce efficiency (increase latency and/or errors) when unrelated primes are used. This pattern is considered in more detail below.

The memory-recruitment account is a radical departure from conventional priming accounts because it allows for flexibility in the basic process that produces priming. In contrast, most accounts of priming at short prime- 
target stimulus onset asynchronies (SOAs) posit underlying processes that are automatic and inflexible (e.g., Forster, Mohan, \& Hector, 2003; Neely, 1991). Forster and Davis (1984) proposed that masking prevents the formation of the memory representations that drive priming according to the memory-recruitment account. In Forster and Davis's lexical-entry opening account, presentation of a prime causes its entry in a mental lexicon to be automatically preactivated, or opened, thus producing a savings in response time (RT) on repetition trials relative to unrelated trials (for reviews, see Forster, 1998, and Forster et al., 2003). Because entry opening is viewed as automatic, the context sensitivity shown by prime-proportion effects must be attributed to an additional nonlexical process. For example, the decision-making process involved in the lexical decision task might be sensitive to the frequent occurrence of matching lexical entries for prime and target items in the high-RP condition. With frequent repetition primes, the decision process might rely on an abbreviated check for a prime-target match and respond positively when such a match is found.

\section{The Proportion-Bias Pattern and Its Theoretical Importance}

We propose that the form taken by prime-proportion effects places an important constraint on accounts of masked priming. According to the memory-recruitment account, reliance on masked primes increases when the proportion of task-valid (e.g., repetition, semantic, matching parity) primes is higher. Increased prime reliance should result in increased facilitation from valid primes and should result in increased interference from invalid primes, resulting in a bias effect (e.g., Ratcliff, McKoon, \& Verwoerd, 1989). As summarized in Bodner and Dypvik (2005), high-validity groups tend to respond faster than do low-validity groups on valid trials (a facilitation effect) while making more errors (and/or responding more slowly) on invalid trials (an interference effect). The simultaneous increase in facilitation and interference when the proportion of valid-prime trials is higher (which we term a proportion-bias pattern), has now been shown with words (Bodner \& Masson, 2001), numbers (Bodner \& Dypvik, 2005), and nonalphanumeric stimuli (Jaskowski et al., 2003), each time using a different task.

Davis (2003) noted that the lexical entry-opening account predicts that "an unrelated prime condition should result in equivalent performance to an unprimed target condition" (p. 132), because opening the lexical entry for an unrelated prime should have no bearing on the opening of the target's entry. Indeed, Forster et al. (2003) stated that many lexical entry opening processes "can be initiated in parallel without additional cost" (p. 17). The entry-opening account thus does not predict interference from unrelated primes, and, furthermore, given that it does not account for prime-proportion effects, it follows that it also does not predict that interference will be greater when RP is higher (i.e., the interference part of the proportion-bias pattern).

Davis (2003) also noted, however, that certain competitive activation-based network accounts - in particular, McClelland and Rumelhart's (1981) interactive-activation
(IA) account - can predict interference from some types of unrelated word primes. In the IA model, interference occurs when activation of the unrelated word prime's word-level representation competes with activation of the target word's word-level representation. Davis (2003) provided a detailed account and simulations of the conditions under which the IA model produces interference relative to particular baseline conditions. For present purposes, we simply note that currently, activation-based accountsincluding the IA account-do not contain mechanisms that are sensitive to cross-trial contextual factors, such as the proportion of various types of primes. As a result, it is unclear how such accounts will accommodate the effects of prime-proportion manipulations and the proportionbias pattern they produce.

\section{The Present Study}

Given the theoretical importance of prime-proportion effects, in the present experiments we more closely examined their form. A potential concern with extant proportion-bias demonstrations is that they have been shown using only between-group comparisons. That is, the facilitation component was evidenced by (1) faster responses on valid trials and (2) more error-prone (and/or slower) responses on invalid trials in the high-proportion group than in the low-proportion group. A drawback to this between-group method is that data from several experiments often must be pooled to obtain enough power to detect both components (Bodner \& Dypvik, 2005; Bodner \& Masson, 2001). A second drawback of relying solely on between-group comparisons is that facilitation or interference is never demonstrated within a given group. Put simply, it cannot be determined whether using a high RP increases the degree to which repetition primes facilitate responses or to which unrelated primes interfere with responses.

These limitations of the between-group method led us to employ a baseline method of computing facilitation and interference, which we used to specify how RP affects masked priming of lexical decisions. To this end, a set of baseline trials with primes that were expected to have little effect on target processing were included in each RP group. For reasons discussed later, we first tried a baseline prime consisting of unique consonant strings and then moved to a no-prime (i.e., a blank screen) baseline. Adding a baseline condition provides a within-condition comparison for gauging facilitation and interference, while still allowing the between-group method to be used to provide converging evidence of a proportion-bias pattern. Using the baseline method, facilitation is estimated as the difference between repetition-prime trials and baseline trials, and interference is estimated as the difference between unrelated-prime trials and baseline trials; the size of each effect can then be compared across RP conditions to assess whether the increase in priming when RP is higher is due to increased facilitation, increased interference, or both.

Baseline prime conditions have a long history of use for measuring facilitation and interference effects, especially with semantic primes (for reviews, see Jonides \& Mack, 
1984, and Neely, 1991). Fewer studies have used baselines with SOAs less than $250 \mathrm{msec}$, where conscious, strategic use of the primes is thought to be prevented (see Neely, 1991). In most short-SOA studies, facilitation from semantic primes relative to baseline has been reported (e.g., den Heyer, Briand, \& Smith, 1985; Favreau \& Segalowitz, 1983; Neely, 1977; Smith, Briand, Klein, \& den Heyer, 1987; Stone \& Van Orden, 1992). In some studies, interference from unrelated primes relative to baseline has also been found (e.g., de Groot, 1984; de Groot, Thomassen, \& Hudson, 1986). In a few studies, interference has been exclusively found (e.g., Antos, 1979; den Heyer, Briand, \& Dannenbring, 1983).

Use of a baseline prime condition for cost-benefit analyses was critiqued by Jonides and Mack (1984). For example, they pointed out that use of the same baseline prime across trials (e.g., xxxx, blank, ready) may cause it to become less effective at attracting attention or less demanding to process than a nonrepeated baseline prime. We agree that caution is needed when interpreting facilitation and interference relative to a baseline, but we also reasoned that Jonides and Mack's criticisms might apply mainly to studies with visible primes. In the masked priming paradigm, all trials are cued by a premask, thereby equating attention without rendering subjects aware of the primes (e.g., Damian, 2001; Naccache \& Dehaene, 2001). Moreover, if masked primes are processed automatically, as is typically assumed, then differences in processing demands across baseline and nonbaseline conditions should be minimal.

Perhaps due in part to Jonides and Mack's (1984) critique, few studies have included a baseline condition for assessing facilitation and interference from masked primes. Using the lexical decision task and a 60 -msec SOA, Sereno (1991) found $51 \mathrm{msec}$ of facilitation from repetition primes and $12 \mathrm{msec}$ of interference from unrelated primes, relative to a baseline condition consisting of a row of asterisks. In a study of orthographic neighborhood effects in the lexical decision task, Perea and Gotor (1996) used a no-prime baseline and reported that most of the repetition-priming effect in the response latencies at 33- and 50-msec SOAs was due to interference, but significant facilitation emerged at a $67-\mathrm{msec}$ SOA. The results of these studies suggest that both facilitation and interference effects can contribute to masked repetition priming, but the relative amount of facilitation versus interference likely depends in part on the type of baseline used.

The inclusion of a baseline prime condition in our experiments served three functions. First, we wanted to demonstrate that unrelated primes can interfere with masked priming relative to a baseline condition - a result not predicted by the lexical entry opening account. Second, baseline trials were used to provide a within-group measure of whether the increase in priming when the RP is higher is due to increased facilitation on repetition trials, increased interference on unrelated trials, or both. Critically, the memory-recruitment account predicts that increased prime recruitment when the RP is higher should increase both facilitation and interference. By this account, high RP leads to greater reliance on the prime event when processing the target, and this increased use of the prime resource should enhance the benefit of repetition priming while increasing the cost of unrelated priming. Third, baseline trials were used in Experiment 2 to resolve an ambiguity in previous prime-proportion studies - namely, whether the increase in priming when RP is higher is driven by the larger proportion of repetition trials or by the smaller proportion of unrelated trials in that group.

\section{EXPERIMENT 1A}

In Experiment 1A, we used the baseline method to determine whether the increase in priming of lexical decisions when RP is higher is due to greater facilitation from repetition primes, greater interference from unrelated primes, or both. To that end, a unique consonant-string baseline prime (e.g., wrnst, tmwr) was presented on $10 \%$ of the trials in the high-RP and low-RP groups, and performance on these baseline trials was used as a within-group benchmark against which to measure facilitation from repetition primes and interference from unrelated primes.

\section{Method}

Subjects. Sixty undergraduates participated for course credit and were randomly assigned to either the .8-RP group or the .2-RP group ( $n=30$ each). Of these 60 subjects, 48 ( 24 per RP group) were from the University of Victoria and 12 (6 per RP group) were from the University of Calgary.

Materials and Design. The targets were 220 words and 220 pronounceable nonwords, three to eight letters in length, used in Bodner and Masson (2003). Twenty of each type were used for practice trials. The 200 critical word targets ranged in frequency from 1 to 2,216 per million (median $=31$; Kučera \& Francis, 1967), and 154 of them had frequencies lower than 100 per million. Each critical word and nonword target was paired with a unique unrelated word prime of the same length and from the same frequency range (median $=30$ ). Each unrelated prime shared no more than two letters with its target and shared no letters in the same letter position.

Each of the critical word and nonword targets were separated into 10 sets of 20 items for assignment to prime conditions. In the .8-RP group, eight sets of word targets were assigned repetition primes (.8), one set was assigned unrelated primes (.1), and one set was assigned unique consonant-string baseline primes (.1). In the .2-RP group, two sets of word targets were assigned repetition primes (.2), seven sets were assigned unrelated primes (.7), and one set was assigned unique consonant-string baseline primes (.1). In both RP groups, nine sets of nonword targets were assigned unrelated word primes (.9), and one was assigned unique consonant-string baseline primes (.1). The assignment of the 10 word and nonword sets to the priming conditions was counterbalanced across subjects. The RP of the 40 practice items matched that of the 400 critical items. The critical trials were divided into four blocks of 100 trials (50 word and 50 nonword trials) such that the same proportion of each prime type was presented within each block. Order of presentation of items within a block was randomized.

Procedure. The subjects were tested individually using a Macintosh computer. Each trial began with a $493-\mathrm{msec}$ mask, consisting of a row of uppercase $X \mathrm{~s}$ of the same length as the prime and the target. The mask was immediately followed by a $45-\mathrm{msec}$ prime in lowercase letters. The prime was immediately followed by a target in uppercase letters that remained on the screen until the subject responded. The 12-point Courier font stimulus displays were synchronized with the raster scan cycle of the monitor to produce precise 
timing of displays. A four-letter word subtended a horizontal visual angle of $1.4^{\circ}$ when viewed from a distance of $40 \mathrm{~cm}$.

The subjects were informed that several briefly displayed items would be shown on each trial in the center of the screen and that their task was to categorize the uppercase letter string that followed the row of $X \mathrm{~s}$ as a word or nonword as quickly and accurately as possible by pressing one of two keys. They were not specifically informed about the primes. Using a button box, the subjects pressed the YES key with the right index finger if the target was a word and pressed the No key with the left index finger if the target was not a word. A corrective feedback message appeared on the monitor for $1 \mathrm{sec}$, accompanied by a tone on trials in which an incorrect response was made (INCORRECT RESPONSE) or when the response latency exceeded $1,500 \mathrm{msec}$ (TOO SLOW). The next trial began $1 \mathrm{sec}$ after a correct response or corrective feedback.

The 40 practice trials were presented in a random order, followed by the four blocks of critical trials, within each of which the trials were presented in a random order. A rest break followed every 50 critical trials. After the lexical decision task, the subjects were asked what they had seen on each trial, just prior to the appearance of the target word. If they initially reported seeing only $X \mathrm{~s}$, which was a typical response, they were asked follow-up questions to assess whether they were subjectively aware of the primes or not (e.g., "Did you see anything else, after the row of $X$ s but before the target appeared?").

\section{Results}

Reported prime awareness. Seventeen percent of the .8 -RP group and $23 \%$ of the .2-RP group were classified as prime aware, meaning that they reported awareness of the prime on at least one trial (whether or not they could identify it). To examine whether reported prime awareness influenced the results, separate analyses were performed on the data from all subjects (the full data set) and on the data excluding these prime-aware subjects (the unaware data set). As we have consistently found (Bodner \& Dypvik, 2005; Bodner \& Masson, 2003, 2004), the results were very similar in both data sets. For brevity, results reported as significant were significant in both sets of analyses unless otherwise noted.

Response latencies and error rates. Trials with response latencies below $300 \mathrm{msec}$ or above $3 \mathrm{sec}$ were excluded in each of the experiments we report (less than $0.5 \%$ of trials per experiment; Ulrich \& Miller, 1994). Because our emphasis was on the locus of RP effects shown for words, only descriptive statistics are reported for nonwords. The mean latencies and error rates for nonwords were $698 \mathrm{msec}$ and $4.9 \%$ in the .2 -RP group and $647 \mathrm{msec}$ and $4.8 \%$ in the .8 -RP group. The mean latencies, percent error, and associated confidence intervals for word targets are displayed in Figure 1. The ANOVA results are presented in Table 1. Here, we emphasize whether each pair of prime type conditions differed and whether each difference interacted with RP (there was almost never a main

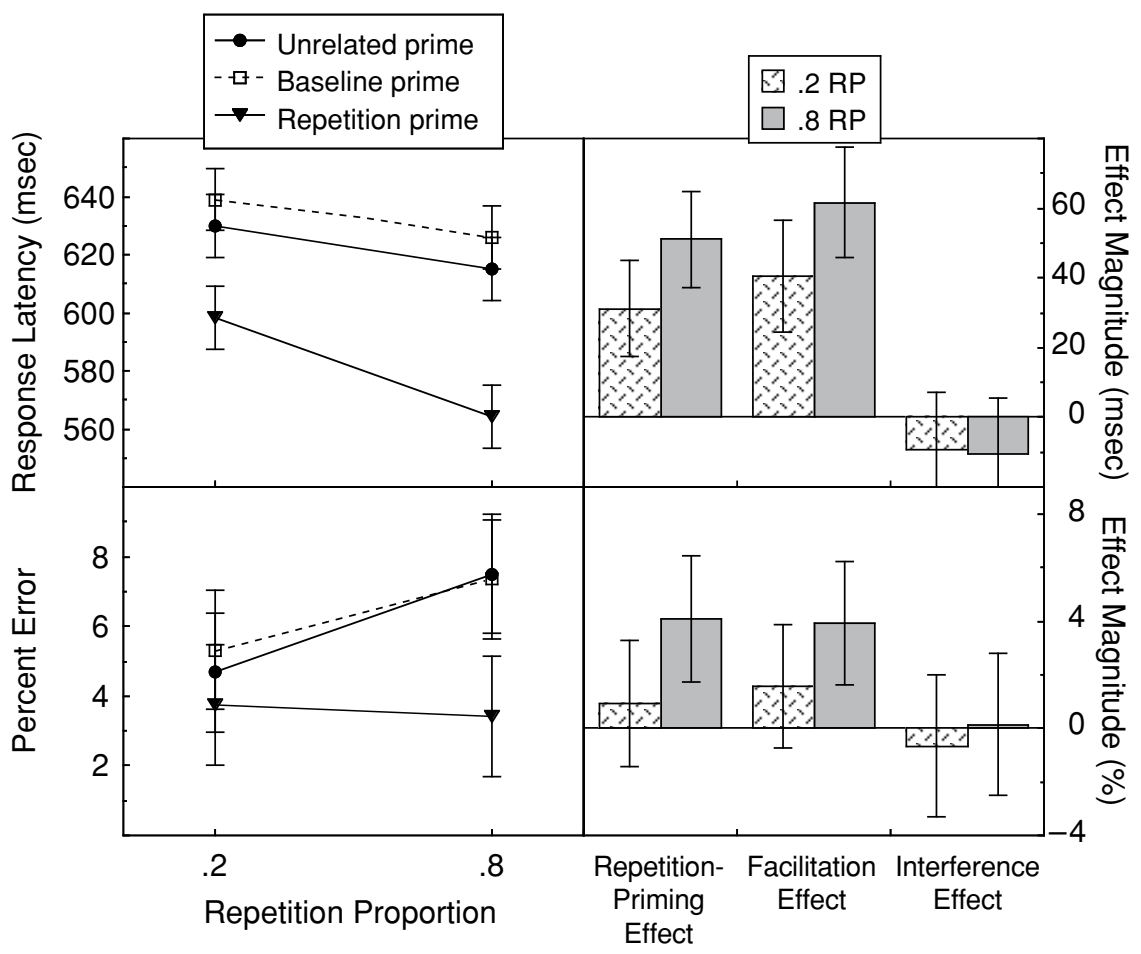

Figure 1. Mean response latency and error rate as a function of prime type and repetition proportion (left panels) and mean repetition-priming effect, facilitation effect, and interference effect as a function of repetition proportion (right panels), for word targets in Experiment 1A. Error bars for response latencies and error rates (left panels) are $95 \%$ withinsubjects confidence intervals and are appropriate for comparing means across prime types (see Loftus \& Masson, 1994; Masson \& Loftus, 2003). Error bars for the various effects (right panels) are $95 \%$ between-subjects confidence intervals and are appropriate for comparing means across repetition proportion groups and against zero. 
Table 1 Priming, Facilitation, and Interference Effect ANOVA Results in Experiment 1A

\begin{tabular}{|c|c|c|c|c|c|c|c|c|}
\hline \multirow[b]{3}{*}{ Analysis/Effect } & \multicolumn{4}{|c|}{ Response Latency } & \multicolumn{4}{|c|}{ Percent Error } \\
\hline & \multicolumn{2}{|c|}{ Full } & \multicolumn{2}{|c|}{ Unaware } & \multicolumn{2}{|c|}{ Full } & \multicolumn{2}{|c|}{ Unaware } \\
\hline & $F(1,58)$ & $M S_{\mathrm{e}}$ & $F(1,46)$ & $M S_{\mathrm{e}}$ & $F(1,58)$ & $M S_{\mathrm{e}}$ & $F(1,46)$ & $M S_{\mathrm{e}}$ \\
\hline \multicolumn{9}{|l|}{ Priming (U vs. R) } \\
\hline $\mathrm{RP}(.8$ vs. .2) & 1.95 & 9,249 & 1.10 & 10,778 & 1.31 & 35.5 & 1.11 & 40.3 \\
\hline Prime type & $70.22^{*}$ & 722 & $50.01^{*}$ & 730 & $9.17^{*}$ & 20.5 & $6.79^{*}$ & 23.4 \\
\hline $\mathrm{RP} \times$ prime type & $4.11^{*}$ & 722 & $3.16^{* *}$ & 730 & $3.65^{* *}$ & 20.5 & $5.44^{*}$ & 23.4 \\
\hline \multicolumn{9}{|l|}{ Facilitation (B vs. R) } \\
\hline RP (.8 vs. .2) & 1.73 & 9,857 & .83 & 11,595 & .54 & 39.1 & .45 & 45.2 \\
\hline Prime type & $81.63^{*}$ & 960 & $55.24^{*}$ & 1,161 & $11.36^{*}$ & 20.1 & $8.67^{*}$ & 22.2 \\
\hline $\mathrm{RP} \times$ prime type & $3.51^{* *}$ & 960 & $2.98^{* *}$ & 1,161 & 2.07 & 20.1 & $3.73^{* *}$ & 22.2 \\
\hline \multicolumn{9}{|l|}{ Interference (U vs. B) } \\
\hline RP (.8 vs. .2) & .69 & 8,407 & .26 & 9,685 & 2.65 & 66.3 & $3.32^{* *}$ & 75.3 \\
\hline Prime type & $2.97^{* *}$ & 1,005 & $3.82^{* *}$ & 1,014 & .07 & 26.6 & .05 & 31.5 \\
\hline $\mathrm{RP} \times$ prime type & .01 & 1,005 & .11 & 1,014 & .18 & 26.6 & .15 & 31.5 \\
\hline
\end{tabular}

Note-RP, repetition proportion; $U$, unrelated prime; $B$, baseline prime; $R$, repetition prime; Full, full data set; Unaware, unaware data set. ${ }^{*} p<.05 .{ }^{* *} .05<p<.10$.

effect of RP). Planned contrasts were used to follow up significant interactions between RP and prime type. The significance level was set at .05 ; marginal results refer to those with significance levels above .05 but below 10 .

Mixed-factor ANOVAs with RP $(.8, .2)$ as the betweensubjects factor and priming (unrelated vs. repetition), facilitation (baseline vs. repetition), or interference (unrelated vs. baseline) as the within-subjects factor were computed on the mean response latencies and error rates. Lexical decisions were $41 \mathrm{msec}$ faster on repetition-prime trials than on unrelated-prime trials. As expected, this repetition-priming effect was significantly larger in the .8-RP group than in the .2-RP group in the full data set (51 vs. $31 \mathrm{msec}$ ) and was marginally larger in the unaware data set. In the error rates, the reduction in errors on repetition trials was marginally larger in the .8-RP group than in the .2-RP group in the full data set (4.1\% vs. $0.9 \%)$, and this interaction was significant in the unaware data set.

We examined facilitation and interference effects relative to the baseline prime condition, to determine whether the increased repetition priming in the high-RP group was due to increased facilitation from repetition primes and/ or increased interference from unrelated primes. Lexical decisions were faster on repetition trials than on baseline trials, and this facilitation effect was marginally larger in the .8-RP group than in the .2-RP group (62 vs. $41 \mathrm{msec}$ ); a similar pattern occurred in the error rates. Thus, we obtained evidence that facilitation from repetition primes, relative to our baseline condition, was somewhat greater when RP was higher. Unexpectedly, however, lexical decisions were marginally slower $(10 \mathrm{msec})$ when preceded by consonant-string primes than when preceded by unrelated words (see Figure 1). The utility of the baseline condition was predicated on our ability to use it to separate repetition priming into facilitation and interference components. Therefore, the observed pattern of means prevented us from using the baseline condition to assess interference from unrelated primes. There was no interaction between prime condition (unrelated vs. baseline) and RP, nor were there any significant effects in the error rates.

\section{Discussion}

The results of Experiment 1A confirmed Bodner and Masson's (2001) finding of greater masked repetition priming in the lexical decision task when the RP was .8 than when it was .2. In addition, a consonant-string prime baseline was used to measure facilitation and interference across RP conditions. Unfortunately, responses were somewhat slower on baseline trials than on unrelatedprime trials, so it was not possible to separate repetition priming into facilitation and interference components. We suggest that this pattern most likely reflects masked response priming: a cost on trials in which the masked prime and the target are associated with different responses, relative to trials in which the masked prime and target fit the same response (e.g., Klinger, Burton, \& Pitts, 2000; Neumann \& Klotz, 1994). The consonant-string baseline primes we used were nonwords and hence would bias an incorrect (i.e., nonword) response, whereas the unrelatedword primes used in the unrelated-prime condition would bias a correct (i.e., word) response.

The possibility of response priming adds to the list of concerns raised by Jonides and Mack (1984) regarding the use of a baseline condition. Repeatedly used baseline word primes, such as blank or ready, may bias a word response, and any baseline prime that is not a word, such as $x x x x, c r w k$, or a row of asterisks, may bias a nonword response. We reasoned that a better option might be to use a no-prime baseline, given that the cognitive system is unlikely to take a blank screen as evidence for one response option over another. Assuming that subjects are largely unaware of the primes, and assuming that masked primes are processed automatically, we anticipated that a no-prime condition would provide a more suitable baseline for measuring the change in facilitation and interference across RP conditions in Experiment 1B. 


\section{EXPERIMENT 1B}

In Experiment 1B, we used the same design as that in Experiment 1A, except a 45-msec blank screen was used in place of consonant-string baseline primes.

\section{Method}

Subjects. Forty undergraduates at the University of Victoria participated for course credit; they were randomly assigned to either the .8-RP group or the .2-RP group ( $n=20$ each).

Materials, Design, and Procedure. The only change from Experiment $1 \mathrm{~A}$ was that a blank screen was presented for $45-\mathrm{msec}$ on baseline trials. The no-prime baseline trials were not noticeably different from the trials with repetition or unrelated primes.

\section{Results}

Reported prime awareness. Thirty-five percent of the .8-RP group and $37 \%$ of the .2-RP group were classified as prime aware. The results were again very similar in the full and unaware data set analyses despite the loss of power in the unaware data set. Unless otherwise stated, significant results were significant in both data sets.

Response latencies and error rates. The mean latencies and error rates for nonwords were $710 \mathrm{msec}$ and $4.4 \%$ in the .2-RP group and $667 \mathrm{msec}$ and $4.6 \%$ in the .8 -RP group. The mean latencies and percent error for word targets are displayed in Figure 2, and the ANOVA results are presented in Table 2.
An RP effect occurred in the response latency analysis: Repetition priming $(37 \mathrm{msec})$ was nearly twice as large in the .8-RP group as in the .2-RP group (49 vs. $26 \mathrm{msec}$ ). RP did not modulate the significant repetition priming effect observed in the error rates. Lexical decisions were also faster on repetition trials than on no-prime trials, and this $35-\mathrm{msec}$ facilitation effect was larger in the .8-RP group than in the .2-RP group (52 vs. $19 \mathrm{msec}$ ). Thus, as in Experiment 1A, higher RP led to increased facilitation from repetition primes relative to the baseline condition. There was no facilitation effect or interaction with RP in the error rate analyses.

As Figure 2 illustrates, the change from a consonantstring baseline to a no-prime baseline eliminated the trend for slower responses on baseline trials relative to unrelated-prime trials. Even so, the unrelated-prime trials produced no interference relative to the no-prime trials, and there was no difference in interference as a function of RP. However, an interference effect was found in the error rates in the full data set, and interference was also greater in the .8-RP group than in the .2-RP group (4.8\% and $.01 \%$, respectively); both effects were marginal in the unaware data set.

\section{Discussion}

Experiment 1B's no-prime condition provided a more appropriate baseline for computing facilitation and inter-

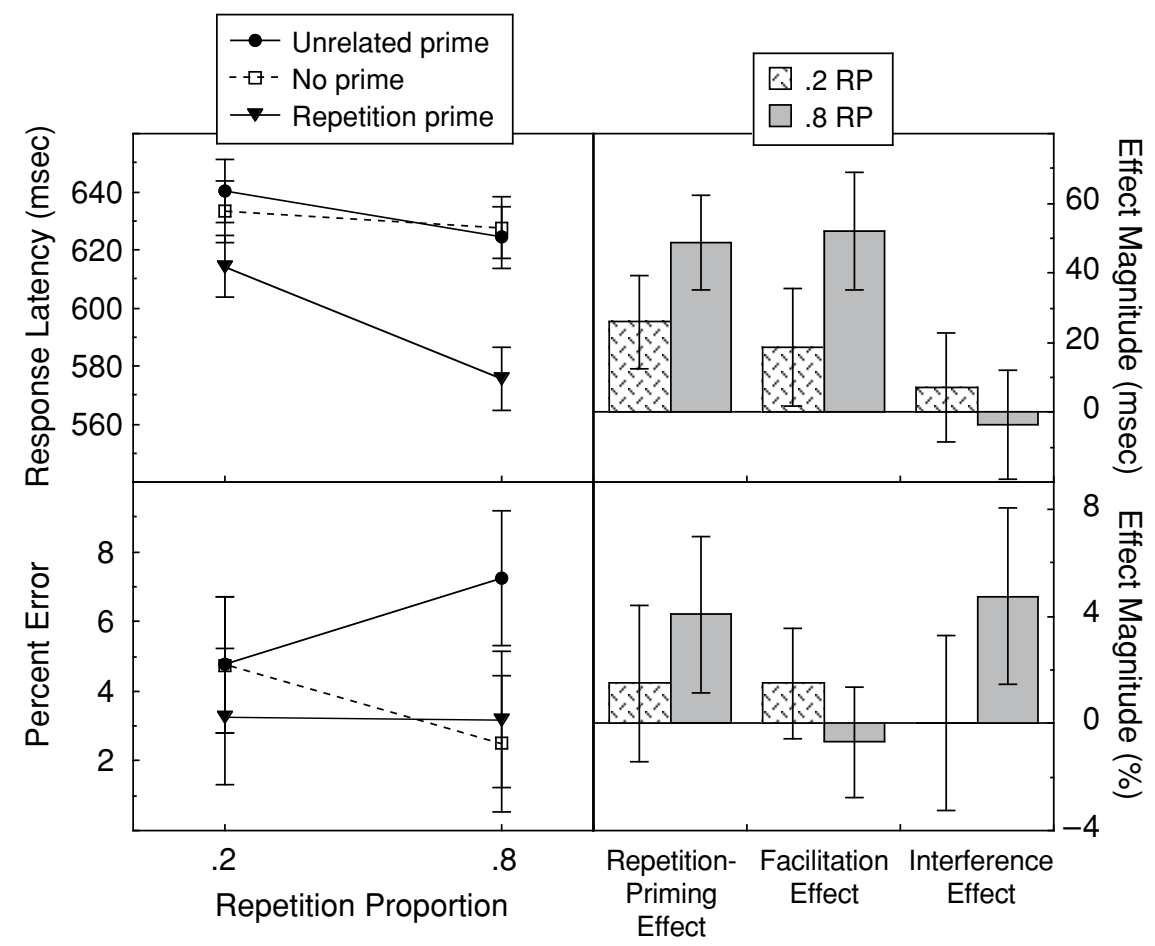

Figure 2. Mean response latency and error rate as a function of prime type and repetition proportion (left panels) and mean repetition-priming effect, facilitation effect, and interference effect as a function of repetition proportion (right panels), for word targets in Experiment 1B. Confidence intervals were computed as in Experiment 1A (see Figure 1 caption). 
Table 2

Priming, Facilitation, and Interference Effect ANOVA Results in Experiment 1B

\begin{tabular}{|c|c|c|c|c|c|c|c|c|}
\hline \multirow[b]{3}{*}{ Analysis/Effect } & \multicolumn{4}{|c|}{ Response Latency } & \multicolumn{4}{|c|}{ Percent Error } \\
\hline & \multicolumn{2}{|c|}{ Full } & \multicolumn{2}{|c|}{ Unaware } & \multicolumn{2}{|c|}{ Full } & \multicolumn{2}{|c|}{ Unaware } \\
\hline & $F(1,38)$ & $M S_{\mathrm{e}}$ & $F(1,25)$ & $M S_{\mathrm{e}}$ & $F(1,38)$ & $M S_{\mathrm{e}}$ & $F(1,25)$ & $M S_{\mathrm{e}}$ \\
\hline \multicolumn{9}{|l|}{ Priming (U vs. R) } \\
\hline RP (.8 vs. .2) & 2.06 & 7,319 & .38 & 7,757 & 1.05 & 28.0 & .78 & 37.2 \\
\hline Prime type & $63.78^{*}$ & 437 & $56.18^{*}$ & 373 & $7.52^{*}$ & 20.5 & $5.13^{*}$ & 24.4 \\
\hline $\mathrm{RP} \times$ prime type & $5.94^{*}$ & 437 & $8.03^{*}$ & 373 & 1.60 & 20.5 & $3.54^{* *}$ & 24.4 \\
\hline \multicolumn{9}{|l|}{ Facilitation (B vs. R) } \\
\hline RP (.8 vs. .2) & 1.22 & 8,086 & .13 & 8,817 & 2.18 & 12.3 & $3.04^{* *}$ & 11.4 \\
\hline Prime type & $36.15^{*}$ & 695 & $28.79^{*}$ & 771 & .31 & 10.4 & .20 & 10.8 \\
\hline $\mathrm{RP} \times$ prime type & $7.97^{*}$ & 695 & $7.24^{*}$ & 771 & 2.30 & 10.4 & .36 & 10.8 \\
\hline \multicolumn{9}{|l|}{ Interference (U vs. B) } \\
\hline RP (.8 vs. .2) & .32 & 7,344 & .05 & 7,934 & .01 & 31.1 & .33 & 35.7 \\
\hline Prime type & .12 & 600 & .02 & 738 & $4.31^{*}$ & 26.2 & $3.07^{* *}$ & 30.6 \\
\hline $\mathrm{RP} \times$ prime type & .92 & 600 & .54 & 738 & $4.29^{*}$ & 26.2 & $4.16^{* *}$ & 30.6 \\
\hline
\end{tabular}

Note-RP, repetition proportion; U, unrelated prime; $B$, baseline prime; R, repetition prime; Full, full data set; Unaware, unaware data set. ${ }^{*} p<.05 .{ }^{* *} .05<p<.10$.

ference effects, in contrast to the consonant-string baseline in Experiment 1A, which produced slower responding relative to the unrelated-prime condition. Use of the baseline method revealed that the RP effect comprises both facilitation and interference components. Relative to the no-prime baseline, the subjects in the .8 -RP group were faster than those in the 2 -RP group on repetitionprime trials (a facilitation effect); however, the subjects in the .8-RP group also made more errors on unrelatedprime trials (an interference effect). This represents the first demonstration of a proportion-bias pattern using the baseline method.

A potential drawback of the baseline method is that the choice of baseline condition will affect the relative size of facilitation versus interference effects. A comparison of the baseline means across Experiments $1 \mathrm{~A}$ and $1 \mathrm{~B}$ illustrates this point. Heeding the cautions of Jonides and Mack (1984), we do not claim that either of our baseline conditions represents a "truly neutral baseline." For this reason, we did not compare the absolute size of facilitation versus interference effects within a given RP group. Instead, we used the baseline trials as a common benchmark in each RP group, in order to demonstrate that the .8-RP group showed relatively more facilitation from repetition primes and relatively more interference from unrelated primes than did the .2-RP group.

In previous studies, we relied on the between-group method of computing facilitation and interference (Bodner \& Dypvik, 2005; Bodner \& Masson, 2001). One drawback to this method is that there is no demonstration of facilitation or interference within each group. A second drawback is that experiments typically have to be pooled to provide enough power to detect each component of the proportion-bias pattern (cf. when prime-proportion is varied across blocks; Jaskowski et al., 2003). However, the upside of the between-group method is that it does not rely on an always-debatable choice of baseline condition.

To show that our conclusions do not depend on our use of the baseline method, we pooled the full data sets from Experiments $1 \mathrm{~A}$ and $1 \mathrm{~B}(n=50$ per RP group $)$ - in which the repetition and unrelated conditions behaved very similarly - and estimated facilitation (in the response latencies) and interference (in the error rates) using the between-group method. The .8-RP group was a significant $36 \mathrm{msec}$ faster than the 2 -RP group on repetition trials (a facilitation effect) $\left[F(1,98)=6.46, M S_{\mathrm{e}}=5,079\right]$ and also made a significant $2.7 \%$ more errors on unrelated trials (an interference effect) $\left[F(1,98)=4.24, M S_{\mathrm{e}}=42.7\right]$. The between-group and baseline methods thus provided converging evidence for the proportion-bias pattern.

On a different note, in Experiments $1 \mathrm{~A}$ and $1 \mathrm{~B}$, the primes used on nonword target trials were always unrelated words, as is typically the case in studies of relatednessproportion effects (see Neely, 1991). In contrast, Bodner and Masson (2001) always paired nonword primes with nonword targets. By using word primes on both word and nonword trials, we rule out any possible contribution of the lexical status of the primes to priming or to RP effects (a potential cause for concern, given the interference from consonant-string nonword primes in Experiment 1A). The downside of this design is that detection (at some level) of a repetition relation between a prime and a target indicates that the target is a word. Fortunately, the similarity of the RP effect and proportion-bias pattern here and in Bodner and Masson (2001) suggests that the use of word primes rather than nonword primes for nonword targets was not critical.

\section{EXPERIMENT 2}

The RP effects in Experiments 1A and 1B were consistent with Bodner and Masson's (2001) claim that the cognitive system increases its reliance on masked primes when the proportion of repetition-prime trials is high. However, the results of all masked-priming studies of the RP effect to date (Experiments $1 \mathrm{~A}$ and 1B; Bodner \& Masson, 2001, 2003, 2004) have also been consistent with an alternative claim - namely, that reliance on masked primes increases when the proportion of unrelated-prime trials is low. Indeed, Jaskowski et al. (2003) suggested that subjects monitor their error rate and that their responding 
is based more heavily on the proportion of invalid (e.g., unrelated) trials than on the proportion of valid (e.g., repetition) trials.

In Experiment 2, our purpose was to use a no-prime baseline condition to tease apart these two possibilities. Including no-prime trials allowed us to remove the usual confound in which the higher RP group receives a lower proportion of unrelated-prime trials. We accomplished this by using three groups yoked into two pairs. Groups 1 and 2 each received a .2 RP, but the proportion of unrelated-prime trials (or UP, for unrelated proportion) was varied (.6 vs. .2) by varying the proportion of no-prime trials in each group. If repetition priming increases when UP is higher, as suggested by Jaskowski et al. (2003), then the .2-UP group should show more repetition priming than the .6-UP group. Groups 2 and 3 each received a .2-UP, but the RP was varied (.2 vs. .6). If repetition priming increases when RP is higher, as Bodner and Masson (2001) implied, then the .6-RP group should show more repetition priming than the two .2-RP groups (i.e., an RP effect), and the two .2-RP groups should show similar amounts of priming. The no-prime trials were included primarily to dissociate RP from UP, but they also afforded an opportunity to examine the proportion-bias pattern again.

\section{Method}

Subjects. One hundred five undergraduates from the University of Calgary were randomly assigned to one of three groups $(n=35$ each); they participated in exchange for course credit.

Materials, Design, and Procedure. The stimuli and the procedure were the same as those in Experiments 1A and 1B. The critical word targets and nonword targets were separated into five sets of 20 items for counterbalanced assignment of prime type across subjects. In the .2-RP (.6-UP) group, one set of words was assigned repetition primes (.2), three sets were assigned unrelated primes (.6), and one set was not assigned primes (.2). In the .2-RP (.2-UP) group, one set of words was assigned repetition primes (.2), one set was assigned unrelated primes (.2), and three sets were not assigned primes (.6). In the .6-RP (.2-UP) group, three sets of words were assigned repetition primes (.6), one set was assigned unrelated primes (.2), and one set was not assigned primes (.2). For nonword targets, items were assigned to prime conditions (no prime vs. unrelated-word prime) so that the proportion of no-prime trials was the same for word and nonword target trials within each group. The same proportion of each prime type was used for the 40 practice items. The 400 critical trials were divided into four blocks of 100 trials, as described in Experiment 1A.

\section{Results}

Reported prime awareness. On the basis of responses to questions about prime awareness, $17 \%$ of the $.2-\mathrm{RP}$ (.6-UP) group, $28 \%$ of the .2-RP (.2-UP) group, and 20\% of the .6-RP (.2-UP) group were considered prime aware. Again, the results were very similar in the full and unaware data set analyses. Unless otherwise stated, significant results were significant in both data sets.

Response latencies and error rates. The mean response latencies and error rates for nonword targets were $648 \mathrm{msec}$ and 5.3\% in the .2-RP (.6-UP) group, $664 \mathrm{msec}$ and $4.4 \%$ in the .2-RP (.2-UP) group, and $662 \mathrm{msec}$ and $4.7 \%$ in the .6-RP (.2-UP) group. Figure 3 displays the word target means.
There were no differences between the two .2-RP groups in the analyses of priming, facilitation, or interference effects, nor were there any interactions between group and prime type (Table 3). On the basis of these analyses, we conclude that masked priming was not influenced by UP. The .2-RP groups were therefore pooled to increase the power to detect differences in facilitation and interference relative to the .6-RP group.

Turning to comparisons of the pooled 2-RP group to the .6-RP group (Table 4), repetition priming was greater in the .6-RP group than in the .2-RP group ( $42 \mathrm{vs} .30 \mathrm{msec})$. The significant $2.4 \%$ repetition-priming effect in the error rates did not interact with RP. Using the baseline method, most of the priming in Experiments 1A and 1B was due to facilitation from repetition primes (as in Sereno, 1991). In Experiment 2, by contrast, most of the priming was due to interference from unrelated primes (as in Perea \& Gotor, 1996). Although the facilitation effect in Experiment 2 was small, it was significant, and, most importantly, as in Experiment 1, it was larger in the .6-RP group than in the .2-RP group (16 vs. $2 \mathrm{msec}$ ). The errors rates showed a reliable $1.4 \%$ facilitation effect that was not affected by RP. The significant 27-msec interference effect in the response latencies was not modulated by RP. The error rates also showed a significant $1.0 \%$ interference effect, and, although the .6-RP group did not show more interference from unrelated primes than the .2-RP group in the full data set $(2.8 \%$ vs. $0.5 \% ; p=.13)$, this interaction reached significance in the unaware data set.

\section{Discussion}

Although the manipulation of RP was weaker in Experiment 2 (.6 vs. .2) than in Experiments 1A and 1B (.8 vs. .2), the RP effect and the proportion-bias pattern emerged again. Using the baseline method, the .6-RP group showed more facilitation from repetition primes (faster response latencies) and somewhat more interference from unrelated primes (higher error rates) than the pooled .2-RP groups. In contrast, varying UP while keeping RP at .2 had no effect on priming, facilitation, or interference effects. These results suggest that RP rather than UP dictates the cognitive system's level of reliance on masked primes.

The shift from facilitation-dominant priming in Experiment $1 \mathrm{~B}$ to interference-dominant priming in Experiment 2 was unexpected. This discrepancy might have been due to the weaker RP manipulation or the larger proportion of no-prime trials in Experiment 2. Experiments 1A, 1B, and 2 were also mostly conducted in different labs, making it possible that subtle differences (e.g., in monitor displays) rendered the no-prime trials differentially salient. It appears that not only can different baseline conditions behave differently (Experiment 1A vs. Experiment 1B) but the same baseline condition can also behave differently across variations in testing conditions (Experiment 1B vs. Experiment 2). The instability of the baseline condition across experiments (relative to the stable behavior of the repetition- and unrelated-prime conditions) suggests that the between-group method of computing facilitation and interference effects may be preferable. 


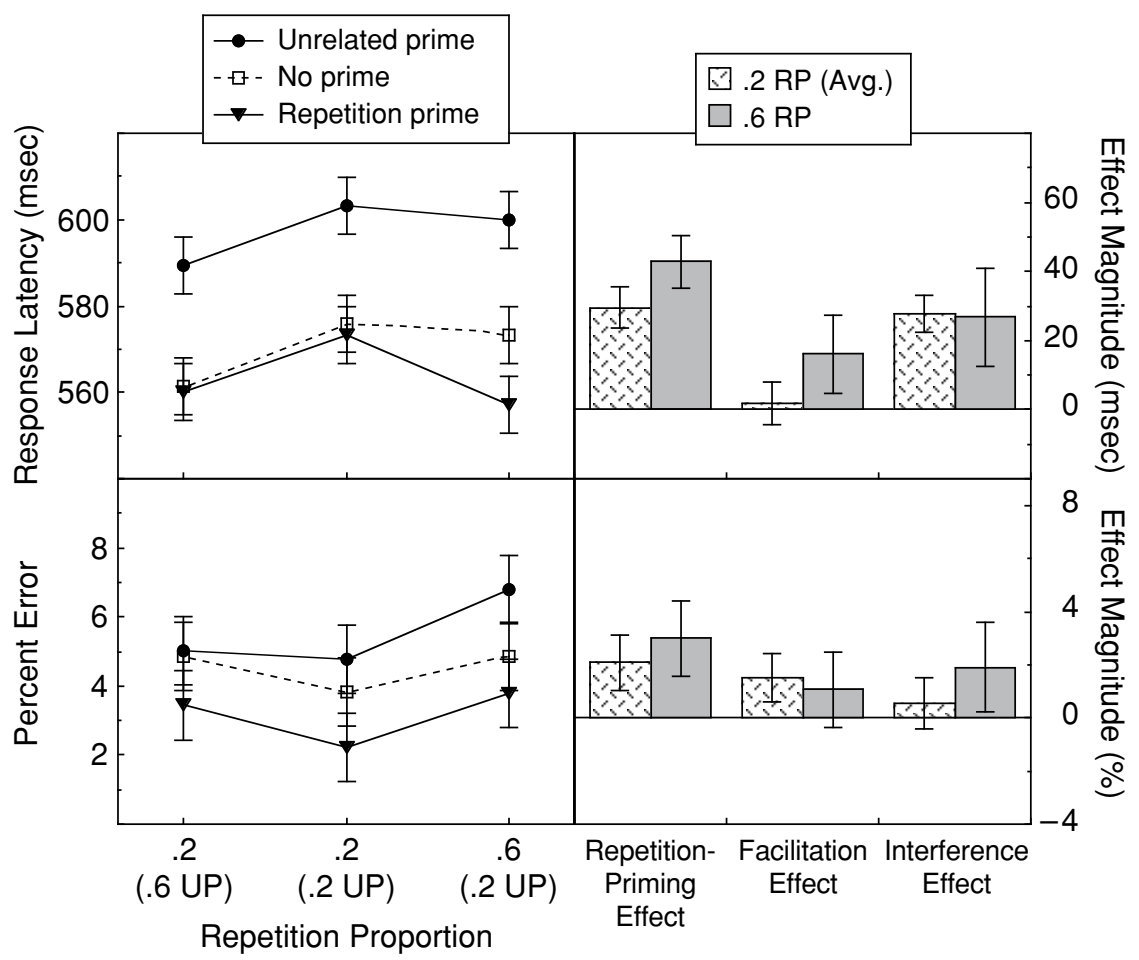

Figure 3. Mean response latency and error rate as a function of prime type and repetition proportion and unrelated proportion (UP) (left panels) and mean repetition-priming effect, facilitation effect, and interference effect as a function of repetition proportion (right panels), for word targets in Experiment 2. Error bars for response latencies and error rates (left panels) are $95 \%$ within-subjects confidence intervals and are appropriate for comparing means across prime conditions. The .2-RP groups were pooled in the right panel. Separate $\mathbf{9 5 \%}$ confidence intervals were computed for each mean in the right panel because of unequal group sizes and are appropriate for comparing each mean against zero.

On the other hand, unpublished data (Bodner \& Brewer, 2006) collected in the lab used in Experiments $1 \mathrm{~A}$ and $1 \mathrm{~B}$ and using the same procedure (45-msec SOA; lexicaldecision task; low-frequency words) confirmed that both facilitation and interference can contribute to masked repetition priming within the same data set (and within the same dependent measure). In these experiments, the RP was .5 , the UP was .25 , and the remaining .25 of the trials involved one of two kinds of baseline primes (lowercase $z$ S vs. pseudoletter strings; $n=28$ per condition). The type of baseline prime did not affect priming, facilitation, or interference, but the main point of relevance here is that the 43-msec priming effect comprised $28 \mathrm{msec}$ of facilitation and $15 \mathrm{msec}$ of interference, each of which was significant. Hence, both effects likely contribute to masked priming, even though their relative contributions appear to depend on aspects of the test situation that remain to be specified.

\section{GENERAL DISCUSSION}

We used a baseline condition to examine why masked repetition priming of words in the lexical decision task is often greater when the proportion of repetition-prime trials is relatively high (Bodner \& Masson, 2001). Do the subjects in a high-RP group benefit more from repetition primes, or do they incur a greater cost from unrelated primes? The results of our experiments suggest that both changes occur. The high-RP groups gained more facilitation from repetition primes (faster response latencies) but suffered more interference from unrelated primes (increased rate of errors). Below, we suggest that this proportion-bias pattern has important implications for accounts of priming.

The proportion-bias pattern was obtained here using two methods. The baseline method relied on a baseline prime condition to gauge facilitation and interference effects, which were then compared across RP conditions. Unfortunately, our baseline conditions were rather unstable across experiments. To begin, responses on baseline trials in Experiment 1A were somewhat slower than on unrelated-prime trials, likely because the consonant-string baseline primes we used were, of course, nonwords, which may have created a bias toward a nonword response to the word targets (e.g., Klinger et al., 2000). For this reason, we moved to a no-prime baseline, but it produced very different response latency patterns in Experiment 1B (in which performance in the baseline condition was very 
Table 3

Priming, Facilitation, and Interference Effect ANOVA Results Comparing the .2-RP (.6-UP) and .2-RP (.2-UP) Groups in Experiment 2

\begin{tabular}{|c|c|c|c|c|c|c|c|c|}
\hline \multirow[b]{3}{*}{ Analysis/Effect } & \multicolumn{4}{|c|}{ Response Latency } & \multicolumn{4}{|c|}{ Percent Error } \\
\hline & \multicolumn{2}{|c|}{ Full } & \multicolumn{2}{|c|}{ Unaware } & \multicolumn{2}{|c|}{ Full } & \multicolumn{2}{|c|}{ Unaware } \\
\hline & $F(1,68)$ & $M S_{\mathrm{e}}$ & $F(1,52)$ & $M S_{\mathrm{e}}$ & $F(1,68)$ & $M S_{\mathrm{e}}$ & $F(1,52)$ & $M S_{\mathrm{e}}$ \\
\hline \multicolumn{9}{|l|}{$\overline{\text { Priming (U vs. R) }}$} \\
\hline UP (.6 vs. .2) & .85 & 7,557 & .83 & 7,245 & .92 & 20.3 & 1.26 & 21.2 \\
\hline Prime type & $92.92^{*}$ & 330 & $64.32^{*}$ & 312 & $15.42^{*}$ & 9.8 & $12.80^{*}$ & 9.7 \\
\hline UP $\times$ prime type & .01 & 330 & .15 & 312 & .88 & 9.8 & .35 & 9.7 \\
\hline \multicolumn{9}{|l|}{ Facilitation (B vs. R) } \\
\hline UP (.6 vs. .2) & .87 & 7,743 & 1.04 & 7,778 & 2.50 & 17.8 & 1.94 & 21.3 \\
\hline Prime type & .34 & 333 & .64 & 277 & $10.52^{*}$ & 7.6 & $9.14^{*}$ & 8.0 \\
\hline UP $\times$ prime type & .04 & 333 & .11 & 277 & .05 & 7.6 & .04 & 8.0 \\
\hline \multicolumn{9}{|l|}{ Interference (U vs. B) } \\
\hline UP (.6 vs. .2) & 1.01 & 6,903 & 1.01 & 6,839 & .56 & 24.8 & .86 & 24.6 \\
\hline Prime type & $104.08^{*}$ & 260 & $67.79^{*}$ & 243 & 1.36 & 8.1 & .85 & 8.0 \\
\hline UP $\times$ prime type & .01 & 260 & .64 & 243 & .68 & 8.1 & .20 & 8.0 \\
\hline
\end{tabular}

Note-RP, repetition proportion; U, unrelated prime; B, baseline prime; R, repetition prime; Full, full data set; Unaware, unaware data set. ${ }^{*} p<.05$.

similar to performance in the unrelated-prime condition) and Experiment 2 (in which baseline performance was very similar to performance in the repetition-prime condition). The similarity between the results of Experiments $1 \mathrm{~A}$ and $1 \mathrm{~B}$ suggests that the facilitation-dominant pattern may be more typical. Nonetheless, Jonides and Mack's (1984) concerns about using a baseline condition to separate priming effects into facilitation and interference components appear to extend even to the masked priming paradigm. Even though the baseline changed substantially across Experiments 1B and 2, it is important to note that the baseline method revealed a proportion-bias pattern in each experiment. The second method of assessing bias that arises from manipulations of RP involves a direct comparison of a given prime condition (repetition, unrelated) across RP groups and thus does not require a baseline condition. This between-group method has con- sistently revealed a proportion-bias pattern, but it has required the pooling of data sets to provide enough power to do so (Experiments 1A and 1B; Bodner \& Dypvik, 2005; Bodner \& Masson, 2001).

Baseline conditions may provide unstable anchors for computing facilitation and interference, but we found that they can serve other uses. In Experiment 2, a no-prime baseline condition proved useful for isolating the contributions of the proportion of repetition primes (RP) versus the proportion of unrelated primes (UP) to the RP effect. Higher RP groups typically have a lower UP (and vice versa), but, in Experiment 2, we removed this confound by including a set of no-prime trials in each RP group so that UP could be varied independently of RP across groups. The results of Experiment 2 confirmed that the RP effect is driven by RP, as Bodner and Masson (2001) claimed, rather than by UP, as suggested by Jaskowski et al. (2003).

Table 4

Priming, Facilitation, and Interference Effect ANOVA Results Comparing the Combined .2-RP Group and the .6-RP Group in Experiment 2

\begin{tabular}{|c|c|c|c|c|c|c|c|c|}
\hline \multirow[b]{3}{*}{ Analysis/Effect } & \multicolumn{4}{|c|}{ Response Latency } & \multicolumn{4}{|c|}{ Percent Error } \\
\hline & \multicolumn{2}{|c|}{ Full } & \multicolumn{2}{|c|}{ Unaware } & \multicolumn{2}{|c|}{ Full } & \multicolumn{2}{|c|}{ Unaware } \\
\hline & $F(1,103)$ & $\overline{M S_{\mathrm{e}}}$ & $F(1,80)$ & $M S_{\mathrm{e}}$ & $F(1,103)$ & $M S_{\mathrm{e}}$ & $F(1,80)$ & $M S_{\mathrm{e}}$ \\
\hline \multicolumn{9}{|l|}{ Priming (U vs. R) } \\
\hline RP $(.2$ vs. .6) & .06 & 7,157 & .13 & 7,141 & $4.61^{*}$ & 20.5 & $3.24^{* *}$ & 22.4 \\
\hline Prime type & $204.72^{*}$ & 300 & $150.96^{*}$ & 290 & $32.40^{*}$ & 9.3 & $32.12^{*}$ & 9.1 \\
\hline $\mathrm{RP} \times$ prime type & $6.90^{*}$ & 300 & $6.29^{*}$ & 290 & 1.06 & 9.3 & 1.94 & 9.1 \\
\hline \multicolumn{9}{|l|}{ Facilitation (B vs. R) } \\
\hline RP (.2 vs. .6) & .04 & 7,670 & .13 & 7,936 & 1.32 & 19.6 & .12 & 22.4 \\
\hline Prime type & $9.21^{*}$ & 404 & $8.14^{*}$ & 384 & $10.00^{*}$ & 7.9 & $6.32^{*}$ & 8.3 \\
\hline $\mathrm{RP} \times$ prime type & $5.87^{*}$ & 404 & $4.34^{*}$ & 384 & .28 & 7.9 & .87 & 8.3 \\
\hline \multicolumn{9}{|l|}{ Interference (U vs. B) } \\
\hline RP (.2 vs. .6) & .12 & 7,074 & .02 & 7,182 & 2.44 & 27.8 & 1.14 & 29.8 \\
\hline Prime type & $77.10^{*}$ & 452 & $47.28^{*}$ & 497 & $7.71^{*}$ & 9.3 & $10.90^{*}$ & 8.9 \\
\hline $\mathrm{RP} \times$ prime type & .02 & 452 & .01 & 497 & 2.29 & 9.3 & $5.35^{*}$ & 8.9 \\
\hline
\end{tabular}

Note - RP, repetition proportion; $\mathrm{U}$, unrelated prime; $\mathrm{B}$, baseline prime; R, repetition prime; Full, full data set; Unaware, unaware data set. ${ }^{*} p<.05 .^{* *} .05<p<.10$. 


\section{Implications of the Proportion-Bias Pattern for Accounts of Masked Priming}

Prime-proportion effects with masked primes have now been shown to conform to a proportion-bias pattern (1) with word stimuli in the lexical decision task (Experiments 1B and 2; Bodner \& Masson, 2001), (2) with number stimuli in number judgment tasks (Bodner \& Dypvik, 2005), and (3) with nonalphanumeric stimuli in a left-right judgment task (Jaskowski et al., 2003). The similarity of these proportion-bias effects - despite differences in task, stimuli, and priming conditions - strongly implicates a domain-general mechanism. Regarding the RP effect, Forster et al. (2003) have held out the hope that "eventually a satisfactory explanation will be found ... that will not compromise the general view of priming as an automatic, nonstrategic, lexical phenomenon" (p. 30). The similarity of prime-proportion effects on masked priming across stimulus domains suggests that at least one of the processes that contributes to masked priming is flexible in ways that have typically been attributed only to controlled processes (see also Greenwald, Abrams, Naccache, \& Dehaene, 2003; Klinger et al., 2000; Naccache, Blandin, \& Dehaene, 2002).

According to the lexical entry opening account, masked repetition priming reflects a savings effect due to preactivation of the target's lexical entry (e.g., Forster, 1998; Forster et al., 2003). If so, opening the lexical entry for an unrelated prime should not have impaired lexical decision accuracy relative to the no-prime baseline in Experiments 1B and 2. In contrast, Davis (2003) has suggested that such interference effects are consistent with certain competitive-activation accounts, such as the IA model (McClelland \& Rumelhart, 1981). In the IA model, interference occurs when the activation of an unrelated word prime's word-level representation competes with the activation of the target word's word-level representation. Importantly, however, it is unclear how either a lexical entry opening process or an interactive-activation process could be influenced by prime proportion. To accommodate such effects, Forster et al. (2003) have suggested it may be necessary to concede that nonlexical processes contribute to masked priming. If such a concession were made, researchers would no longer be able to assume that the masked priming paradigm isolates "lexical" processes from "nonlexical" processes.

Although it warrants further specification, the memoryrecruitment account provides a ready explanation for both priming and prime-proportion effects: Each prime event is encoded, and the resulting processing episode is used to assist with target processing when conditions foster its recruitment. Conditions that encourage prime recruitment include target degradation (Bodner \& Masson, 1997; Whittlesea \& Jacoby, 1990) and high trial-to-trial variability in the ease of target classification (Bodner \& Masson, 2001). The proportion-bias pattern suggests that high levels of prime validity can also foster prime recruitment. Increased prime recruitment results in faster responses on valid trials but results in more errors (and/or slower responses) on the minority of trials in which the prime turns out to be invalid.

Despite these inroads, there may well be ways of explaining prime-proportion effects that do not require a memory-recruitment process at all. For instance, Naccache et al. (2002) found that masked priming requires attention and that task context and cue validity influences how much attention is directed to masked primes. HighRP groups might therefore learn to pay more attention to the prime display than low-RP groups, or low-RP groups might learn to ignore the primes. An attention-based account might handle RP effects without postulating flexibility in the underlying automatic process that produces priming (see Bodner \& Dypvik, 2005).

More radically, the cognitive system may not be directly sensitive to prime validity at all. Instead, subjects may be sensitive to the accuracy or ease of their target responses on recent trials (e.g., Jaskowski et al., 2003), and they may alter their response criteria to maximize task performance (e.g., Lupker, Brown, \& Colombo, 1997). In the naming task, Lupker et al. found a blocking effect, in which naming latencies for easy (e.g., high-frequency) words slowed down when mixed with hard (e.g., low-frequency) words (relative to a pure-easy block), whereas naming of hard words sped up in the mixed block (relative to a pure-hard block). Mozer, Kinoshita, and Davis (2004) suggested that the RP effect may be a form of blocking effect in which the .2- and .8-RP conditions correspond to .2 and .8 easy trials. According to their mathematical adaptation to the statistics of the environment (ASE) model, the setting of the response criterion is determined by both the difficulty of the current trial and the difficulty of recent trials, and the system attempts to initiate a response as soon as possible while minimizing the likelihood of making an error (i.e., when the expected utility is maximized).

Kinoshita, Forster, and Mozer (2006) have extended the ASE model to account for masked RP effects in the naming task (Bodner \& Masson, 2004). The standard ASE model predicts a main effect of RP, rather than the observed interaction of RP and priming, because the model assumes that the effect of the RP context is the same on easy (i.e., repetition) and hard (i.e., unrelated) items. However, given an additional assumption - that unrelated-prime trials will show less speed-up than repetition-prime trials in the high-RP condition - the ASE model is able to predict an asymmetric blocking effect (i.e., an RP effect).

The ASE model shares with the memory-recruitment account the claims that masked priming is sensitive to aspects of the list context and that it responds to this list context flexibly and adaptively. The ASE model, however, offers several potential advantages over the memory-recruitment account. First, being a mathematical model, the ASE model is better specified. Second, the ASE model claims that the cognitive system simply tunes into its performance of a task, rather than directly computing the validity of masked primes (which implies that masked primes are analyzed extensively). Finally, because the ASE process occurs only in speeded tasks, the ASE model is consistent with the 
absence of prime-proportion effects in the masked word identification task (Brysbaert, 2001; Pecher et al., 2002; however, see Bodner \& Masson, 2004, for a discussion of the interpretation of these null findings).

We view the ASE model as a potentially viable alternative to the memory-recruitment account. The model, however, has yet to be applied to binary-decision tasks, in which most prime-proportion effects have been observed. One challenge to such an extension is that it is unclear how the model will explain the interference component of the proportion-bias pattern found here (i.e., the increased error rate on unrelated trials in the high-RP group). The model currently addresses only response-latency effects, and, moreover, it predicts facilitation on both repetitionprime trials and unrelated-prime trials in the high-RP group. Thus, the version of the model developed by Kinoshita et al. (2006) will not produce a proportion-bias pattern in which the higher RP group shows a greater speed-up on repetition trials while also incurring more errors on unrelated trials. Of course, additional modifications to the ASE model may allow it to accommodate the proportion-bias pattern found in binary-decision tasks.

In conclusion, although we have suggested that the source of prime-proportion effects is a context-sensitive memory-recruitment process, alternative proposals now include "prelexical" differences in attention and "postlexical" differences in the setting of response criteria. Development of these latter accounts could preserve the idea that a ballistic mechanism underlies masked priming (e.g., Forster et al., 2003; Greenwald, 1992) while acknowledging that masked priming is also influenced by an additional context-sensitive process that may or may not be consciously controlled.

\section{REFERENCES}

Allen, S. W., \& JACOBY, L. L. (1990). Reinstating study context produces unconscious influences of memory. Memory \& Cognition, 18, 270-278.

Anderson, J. R., \& Milson, R. (1989). Human memory: An adaptive perspective. Psychological Review, 96, 703-719.

Anderson, J. R., \& ScHOOLER, L. J. (1991). Reflections of the environment in memory. Psychological Science, 2, 396-408.

Antos, S. J. (1979). Processing facilitation in a lexical decision task. Journal of Experimental Psychology: Human Perception \& Performance, 5, 527-545.

BoDner, G. E., \& Brewer, A. (2006). Masked repetition priming: Evidence for facilitation and interference. Manuscript in preparation.

Bodner, G. E., \& DypVIK, A. T. (2005). Masked priming of number judgments depends on prime validity and task. Memory \& Cognition, 33, 29-47.

Bodner, G. E., \& Masson, M. E. J. (1997). Masked repetition priming of words and nonwords: Evidence for a nonlexical basis for priming. Journal of Memory \& Language, 37, 268-293.

Bodner, G. E., \& Masson, M. E. J. (1998, November). Repetition prime proportion modulates masked repetition priming. Paper presented at the annual meeting of the Psychonomic Society, Dallas.

Bodner, G. E., \& Masson, M. E. J. (2001). Prime validity affects masked repetition priming: Evidence for an episodic resource account of priming. Journal of Memory \& Language, 45, 616-647.

Bodner, G. E., \& MAsson, M. E. J. (2003). Beyond spreading activation: An influence of relatedness proportion on masked semantic priming. Psychonomic Bulletin \& Review, 10, 645-652.

Bodner, G. E., \& Masson, M. E. J. (2004). Beyond binary judgments:
Prime validity modulates masked repetition priming in the naming task. Memory \& Cognition, 32, 1-11.

Brysbaert, M. (2001). Prelexical phonological coding of visual words in Dutch: Automatic after all. Memory \& Cognition, 29, 765-773.

DAMIAN, M. F. (2001). Congruity effects evoked by subliminally presented primes: Automaticity rather than semantic processing. Journal of Experimental Psychology: Human Perception \& Performance, 27, 154-165.

DAVIS, C. J. (2003). Factors underlying masked priming effects in competitive network models of visual word recognition. In S. Kinoshita \& S. J. Lupker (Eds.), Masked priming: The state of the art (pp. 121170). New York: Psychology Press.

DE Groot, A. M. (1984). Primed lexical decision: Combined effects of the proportion of related prime-target pairs and the stimulus onset asynchrony of prime and target. Quarterly Journal of Experimental Psychology, 36A, 253-280.

de Groot, A. M., Thomassen, A. J., \& Hudson, P. T. (1986). Primedlexical decision: The effect of varying the stimulus onset asynchrony of prime and target. Acta Psychologica, 61, 17-36.

Den Heyer, K., Briand, K., \& Dannenbring, G. L. (1983). Strategic factors in a lexical-decision task: Evidence for automatic and attentiondriven processes. Memory \& Cognition, 11, 374-381.

DEN Heyer, K., Briand, K., \& SMith, L. (1985). Automatic and strategic effects in semantic priming: An examination of Becker's verification model. Memory \& Cognition, 13, 228-232.

Favreau, M., \& Segalowitz, N. S. (1983). Automatic and controlled processes in the first- and second-language reading of fluent bilinguals. Memory \& Cognition, 11, 565-574.

FORSTER, K. I. (1998). The pros and cons of masked priming. Journal of Psycholinguistic Research, 27, 203-233.

Forster, K. I., \& DAVIS, C. (1984). Repetition priming and frequency attenuation in lexical access. Journal of Experimental Psychology: Learning, Memory, \& Cognition, 10, 680-698.

Forster, K. I., Mohan, K., \& Hector, J. (2003). The mechanics of masked priming. In S. Kinoshita \& S. J. Lupker (Eds.), Masked priming: The state of the art (pp. 3-37). New York: Psychology Press.

Greenwald, A. G. (1992). New Look 3: Unconscious cognition reclaimed. American Psychologist, 47, 766-779.

Greenwald, A. G., Abrams, R. L., Naccache, L., \& Dehaene, S. (2003). Long-term semantic memory versus contextual memory in unconscious number processing. Journal of Experimental Psychology: Learning, Memory, \& Cognition, 29, 235-247.

JACOBY, L. L. (1983). Perceptual enhancement: Persistent effects of an experience. Journal of Experimental Psychology: Learning, Memory, \& Cognition, 9, 21-38.

Jaskowski, P., Skalska, B., \& Verleger, R. (2003). How the self controls its "automatic pilot" when processing subliminal information. Journal of Cognitive Neuroscience, 15, 911-920.

Jonides, J., \& MACK, R. (1984). On the cost and benefit of cost and benefit. Psychological Bulletin, 96, 29-44.

Kinoshita, S., Forster, K. I., \& Mozer, M. C. (2006). Modulation of masked repetition priming effect in the word naming task. Manuscript submitted for publication.

Kinoshita, S., \& Lupker, S. J. (EDS.) (2003). Masked priming: The state of the art. New York: Psychology Press.

Klinger, M. R., Burton, P. C., \& Pitts, G. S. (2000). Mechanisms of unconscious priming: I. Response competition, not spreading activation. Journal of Experimental Psychology: Learning, Memory, \& Cognition, 26, 441-455.

Kolers, P. A., \& Roediger, H. L., III (1984). Procedures of mind. Journal of Verbal Learning \& Verbal Behavior, 23, 425-449.

KuČERA, H., \& FRANCIS, W. N. (1967). Computational analysis of presentday American English. Providence, RI: Brown University Press.

Loftus, G. R., \& Masson, M. E. J. (1994). Using confidence intervals in within-subject designs. Psychonomic Bulletin \& Review, 1, 476-490.

Logan, G. D. (1988). Toward an instance theory of automatization. Psychological Review, 95, 492-527.

Lupker, S. J., Brown, P., \& Colombo, L. (1997). Strategic control in a naming task: Changing routes or changing deadlines? Journal of Experimental Psychology: Learning, Memory, \& Cognition, 23, 570-590. 
Masson, M. E. J., \& Bodner, G. E. (2003). A retrospective view of masked priming: Toward a unified account of masked and long-term repetition priming. In S. Kinoshita \& S. J. Lupker (Eds.), Masked priming: The state of the art (pp. 57-94). New York: Psychology Press.

Masson, M. E. J., \& LofTus, G. R. (2003). Using confidence intervals for graphically based data interpretation. Canadian Journal of Experimental Psychology, 57, 203-220.

McClelland, J. L., \& Rumelhart, D. E. (1981). An interactive activation model of context effects in letter perception: I. An account of basic findings. Psychological Review, 88, 375-407.

Morris, C. D., Bransford, J. D., \& Franks, J. J. (1977). Levels of processing versus transfer-appropriate processing. Journal of Verbal Learning \& Verbal Behavior, 16, 519-533.

Mozer, M. C., Kinoshita, S., \& Davis, C. J. (2004). Control of response initiation: Mechanisms of adaptation to recent experience. In K. Forbus, D. Gentner, \& T. Regier (Eds.), Proceedings of the 26th Annual Meeting of the Cognitive Science Society (pp. 981-986). Mahwah, NJ: Erlbaum.

Naccache, L., Blandin, E., \& Dehaene, S. (2002). Unconscious masked priming depends on temporal attention. Psychological Science, 13, 416-424.

NaCCACHe, L., \& Dehaene, S. (2001). Unconscious semantic priming extends to novel unseen stimuli. Cognition, 80, 215-229.

NeEly, J. H. (1977). Semantic priming and retrieval from lexical memory: Roles of inhibitionless spreading activation and limited-capacity attention. Journal of Experimental Psychology: General, 106, 226-254.

NeELY, J. H. (1991). Semantic priming effects in visual word recognition: A selective review of current findings and theories. In D. Besner \& G. W. Humphreys (Eds.), Basic processes in reading: Visual word recognition (pp. 264-336). Hillsdale, NJ: Erlbaum.

Neumann, O., \& Klotz, W. (1994). Motor responses to nonreportable masked stimuli: Where is the limit of direct parameter specification? In C. Umiltà \& M. Moscovitch (Eds.), Attention and performance XV: Conscious and nonconscious information processing (pp. 123-150). Cambridge, MA: MIT Press.
Pecher, D., Zeelenberg, R., \& Raaijmakers, J. G. W. (2002). Associative priming in a masked perceptual identification task: Evidence for automatic processes. Quarterly Journal of Experimental Psychology, 55A, 1157-1173.

Perea, M., \& Gotor, A. (1996). Effects of masked repetition priming and orthographic neighborhood in visual recognition of words. Perceptual \& Motor Skills, 83, 179-186.

Ratcliff, R., McKoon, G., \& Verwoerd, M. (1989). A bias interpretation of facilitation in perceptual identification. Journal of Experimental Psychology: Learning, Memory, \& Cognition, 15, 378-387.

Schooler, L. J., \& Anderson, J. R. (1997). The role of process in the rational analysis of memory. Cognitive Psychology, 32, 219-250.

Sereno, J. A. (1991). Graphemic, associative, and syntactic priming effects at a brief stimulus onset asynchrony in lexical decision and naming. Journal of Experimental Psychology: Learning, Memory, \& Cognition, 17, 459-477.

Smith, L. C., Briand, K., Klein, R. M., \& den Heyer, K. (1987). On the generality of Becker's verification model. Canadian Journal of Psychology, 41, 379-386.

Stone, G. O., \& VAn Orden, G. C. (1992). Resolving empirical inconsistencies concerning priming, frequency, and nonword foils in lexical decision. Language \& Speech, 35, 295-324.

Stone, G. O., \& VAn Orden, G. C. (1993). Strategic control of processing in word recognition. Journal of Experimental Psychology: Human Perception \& Performance, 19, 744-774.

UlRICH, R., \& Miller, J. (1994). Effects of truncation on reaction time analysis. Journal of Experimental Psychology: General, 123, 34-80.

WhittleseA, B. W. A., \& JACOBY, L. L. (1990). Interaction of prime repetition with visual degradation: Is priming a retrieval phenomenon? Journal of Memory \& Language, 29, 546-565.

(Manuscript received October 29, 2004; revision accepted for publication June 28, 2005.) 